University of Nebraska - Lincoln

DigitalCommons@University of Nebraska - Lincoln

Biological Systems Engineering: Papers and

Publications

Biological Systems Engineering

2009

\title{
Plant Sterol and Policosanol Characterization of Hexane Extracts from Grain Sorghum, Corn, and their DDGS
}

\author{
Caolina Leguizamón \\ University of Nebraska-Lincoln \\ Curtis L. Weller \\ University of Nebraska-Lincoln, cweller1@unl.edu \\ Vicki L. Schlegel \\ University of Nebraska-Lincoln, vschlegel3@unl.edu \\ Timothy P. Carr \\ University of Nebraska-Lincoln, tcarr2@unl.edu
}

Follow this and additional works at: https://digitalcommons.unl.edu/biosysengfacpub

Part of the Biological Engineering Commons

Leguizamón, Caolina; Weller, Curtis L.; Schlegel, Vicki L.; and Carr, Timothy P., "Plant Sterol and Policosanol Characterization of Hexane Extracts from Grain Sorghum, Corn, and their DDGS" (2009). Biological Systems Engineering: Papers and Publications. 106.

https://digitalcommons.unl.edu/biosysengfacpub/106

This Article is brought to you for free and open access by the Biological Systems Engineering at DigitalCommons@University of Nebraska - Lincoln. It has been accepted for inclusion in Biological Systems Engineering: Papers and Publications by an authorized administrator of DigitalCommons@University of Nebraska Lincoln. 


\title{
Plant Sterol and Policosanol Characterization of Hexane Extracts from Grain Sorghum, Corn, and their DDGS
}

\author{
Carolina Leguizamón, ${ }^{1}$ Curtis L. Weller, ${ }^{1}{ }^{2}$ Vicki L. Schlegel, ${ }^{1}$ and Timothy P. Carr ${ }^{3}$ \\ 1) Department of Food Science and Technology, University of Nebraska-Lincoln, 143 Filley Hall, Lincoln, \\ NE 68583-0919, USA \\ 2) Department of Biological Systems Engineering, University of Nebraska-Lincoln, 210 L.W. Chase Hall, Lincoln, \\ NE 68583-0726, USA \\ 3) Department of Nutrition and Health Sciences, University of Nebraska-Lincoln, 110 Leverton Hall, Lincoln, \\ NE 68583-0806, USA \\ Corresponding author - Curtis Weller, email cweller1@unl.edu; Carolina Leguizamón, email carolina.leguizamon@gmail.com
}

\begin{abstract}
Plant sterols (PS) and policosanols (PC) have been attributed with plasma cholesterol-lowering properties in humans. Hexane extracts from grain sorghum, corn and their distillers dried grain with solubles (DDGS), an important co-product of ethanol production, contain these health promoting compounds, which could be used to develop health promoting dietary products. However, limited information is currently available regarding optimal methods of extraction and their influence on plant sterol or PC levels and compositions. Therefore, the objective of this study was to quantify lipids, particularly PS and PC extracted from grain sorghum and its DDGS using reflux and Soxtec methods. Corn and its DDGS were also extracted to compare lipid yields and PS/PC compositional profiles in these two related cereals. Intact grains were extracted either as whole or ground kernels. Lipid yields from all the corn sources were typically greater than those obtained from grain sorghum. Lipid yields from DDGS were the highest among all the forms of the grains used whereas corn/sorghum DDGS contained the highest levels of PS and PC, respectively. Additional study demonstrated that hydrolysis (acidic and alkaline) of ground sorghum or sorghum DDGS increased the levels of total extractable plant sterols. Overall, the Soxtec method extracted higher amounts of lipids than the reflux method.
\end{abstract}

Keywords: grain sorghum, corn, DDGS, reflux, soxtec, plant sterols, policosanols, lipids

\section{Introduction}

World-wide interest in the production of alternative fuels has increased in response to current economic, political, and environmental issues. Ethanol is one of the more suitable alternatives because it can be obtained from the fermentation of cereals. Currently, corn is the most popular cereal used for this purpose despite its possible negative environmental impacts [1]. Alternative crops are needed to supplement corn. Additionally, maintaining a diversity of crops grown insures against catastrophic losses caused by weather or disease.

Water scarcity is another growing concern in corn production areas especially in the Midwestern United States; however, grain sorghum is a drought-tolerant crop allowing its cultivation in areas where water is limited [2]. The United States is among the three largest producers of grain sorghum in the world but $50 \%$ of production is exported [3]. Although grain sorghum has applications comparable to corn, given that both are rich in starch, it is often misconceived as an inferior grain. Recently, grain sorghum has been used in the United States to produce ethanol [2] resulting in a major co-product, distillers dried grain with solubles (DDGS). 
Both corn and grain sorghum DDGS are currently used mainly for cattle feed. Their production is expected to exceed the cattle feed requirements in the future. Valuable and beneficial uses of grain sorghum and sorghum DDGS could encourage increased cultivation of grain sorghum.

Recent studies have shown that grain sorghum and its DDGS contain valuable health promoting compounds, such as phenolic acids, tannins, anthocyanins, plant sterols (PS), policosanols (PC) and tocopherols [4, 5]. Plant sterols are widely recognized as serum cholesterol-lowering compounds [6]. In fact, PS is a common dietary ingredient in the United States and the EU, and its health claims on food labels are approved by regulating agencies $[7,8]$. After vegetable oils, cereals are a significant source of PS [9].

PC, also referred to as fatty alcohols, are a waxy material that is high-MW aliphatic alcohols with chain lengths that vary from 24 to 34 carbon atoms. The most common sources of policosanols used for nutritional supplements are sugar cane and beeswax [10]. Similarly to PS, PC have been linked to potential serum lipid-lowering properties [11]. Primary reported PC that have been suggested to contribute to the lowering serum cholesterol levels are octacosanol (C28), triacontanol (C30) and hexacosanol (C26) [11]. These compounds were first approved as a dietary supplement in Cuba [12], and they are currently commercialized in Caribbean and South American countries; however, many researchers outside this region have not obtained the same positive results [13]. As a result, the validity of PC cholesterollowering properties is being questioned.

A recent study [14] showed that grain sorghum lipid extracts reduced cholesterol absorption and plasma nonhigh-density lipoprotein (non-HDL) cholesterol concentration in a hamster model. While the amounts of PS and PC in the extracts were known, no attempt was made to determine the relative contribution of each type of compound in reducing cholesterol absorption and plasma non-high density lipoprotein (non-HDL) cholesterol concentration. Based on the previous work described above, the effect of dietary PS on cholesterol absorption and plasma non-high density lipoprotein (nonHDL) cholesterol concentration is well-known whereas the synergistic effects of PC have yet to be adequately proved or disproved.

Data on PS and PC levels and composition in grain sorghum and DDGS sorghum extracts are limited. Although Piironen et al. [9] investigated the PS content of different cereals and cereal products, grain sorghum and sorghum products were not included in the study. Furthermore, Singh et al. [15] observed types of PS in grain sorghum kernels, grain sorghum wet milling fractions, and comparable corn kernels and corn wet milling fractions. Srinivasan et al. [16] reported PS composition of an unknown commercially produced DDGS sample whereas Winkler et al. [17] investigated corn DDG of Iowa origin. None of these studies had observed PS levels in grain sorghum DDGS and compared it to grain sorghum kernels, corn kernels, and corn DDGS under similar extraction conditions.

If considerable amounts of PS and PC compounds can be extracted from grain sorghum DDGS, important health promoting nutritional supplements and functional food products could be developed. The growth in the use of a sustainable, currently underutilized, cereal would be promoted by adding value to a major co-product, DDGS, of ethanol production from grain sorghum.

In this study, the total lipid yields extractable from grain sorghum and its DDGS with hexane were determined, as well as the PS and PC compositions of the extracts. Whole, ground kernels and DDGS were extracted using reflux and Soxtec extraction methods. Additionally, extractions from yellow dent corn and corn DDGS were performed under the same conditions to compare the results obtained with those from grain sorghum and its DDGS extractions.

\section{Experimental Procedures}

Sorghum, Corn, and Respective DDGS

The grain samples used for the present study were from a food-grade grain sorghum (S. bicolor cultivar: Macia) grown and harvested in the Agronomy plots at the University of Nebraska-Lincoln during 2005. Yellow dent corn hybrid (Pioneer 3363) was obtained from the collections in the Cereal Science Laboratory at the University of Nebraska-Lincoln. The sorghum DDGS was obtained in 2006 from a local ethanol production facility. Energy Partners (now White Energy) in Russell, KS, that processes mixed commercial grain sorghum hybrids. Yellow dent corn DDGS was provided by Nebraska Energy LLC (Aurora, NE). All samples were stored in brown Kraft paper bags at $<0^{\circ} \mathrm{C}$ until used.

Whole corn kernels were ground with a hammer mill set at the highest speed $(4,500 \mathrm{rpm})$ and with a screen size of $2.1 \mathrm{~mm}$. Whole grain sorghum kernels were ground with a coffee grinder for $2 \mathrm{~min}$. Particle size distribution of the ground grains was determined by using the ASAE standard sieving procedure (ANSI/ ASAE S319.3 Feb03) and a sieve shaker equipped with ten sieves (USA standard no. 12, 16, 20, 30, 40, 50, 70, 100,140 and 200) and a pan. Moisture contents of the grain samples were measured following the ASAE S352.2 standard method $\left(103{ }^{\circ} \mathrm{C}\right.$ for $72 \mathrm{~h}$ in a convection oven). 
Reflux Extraction

Reflux extractions were completed with a 3-neck 1,000-mL round-bottom flask connected to a condenser and a thermometer, placed in a mantle heater. Based on results reported in literature [18], a $3 \mathrm{ml}: 1 \mathrm{~g}$ solventto-solids $(\mathrm{wb})$ ratio with typical grain material levels of $200 \mathrm{~g}(\mathrm{wb}), 1 \mathrm{~h}$ extraction time and solvent boiling temperature $\left(\sim 68^{\circ} \mathrm{C}\right)$ were used. Three extractions (replications) of each combination of type and form of cereal were completed. Subsequent to vacuum filtering the solids (no. 2 filter paper, Whatman Int. Ltd., Maidstone, UK) following extraction, the solvent was evaporated from the extracted lipids with a rotary evaporator. Temperature of the water in the evaporator water bath was maintained at $\sim 30{ }^{\circ} \mathrm{C}$ throughout the $\sim 20 \mathrm{~min}$ of solvent evaporation. These samples were then transferred to a $40-\mathrm{mL}$ glass vial, which was then placed and held in a convection oven $\left(38^{\circ} \mathrm{C}\right)$ until the samples reached a constant mass ( $\sim 3$ days). Work by Soupas et al. [19] has shown PS to be relatively stable at this temperature and length of time. The vial with the lipid samples was capped and stored in a freezer at $-10^{\circ} \mathrm{C}$ until analyzed. Lipid recovery yields were determined by dividing the mass of the lipids recovered by the initial mass of the dry grain sample.

\section{Soxtec Extraction}

A Soxtec extractor was used to extract lipids from the different forms of the grains by placing $\sim 5.0 \mathrm{~g}(\mathrm{wb})$ samples in single-thickness cellulose thimbles $(26 \mathrm{~mm}$ I.D. $\times 60 \mathrm{~mm}$ length, $2 \mathrm{~mm}$ thickness, Whatman Int. Ltd., Maidstone, UK). Mass of each glass extraction cup was determined before adding $50 \mathrm{~mL}$ of hexane. Cups were fitted into the Soxtec unit so as to rest on the heating plate. The solvent, submersing each DDGS sample, was refluxed for $1 \mathrm{~h}$ and then rinsed for $2 \mathrm{~h}$. Based on the procedure and results reported by Christiansen et al. [20], the temperature of the heating system was set to $120^{\circ} \mathrm{C}$. After extraction but still warm, the lipids and hexane mixture were transferred from each cup to $40-\mathrm{mL}$ vials. To remove the solvent, the vials and cups with residual mixtures were placed in a convection oven at $38^{\circ} \mathrm{C}$ until a constant weight was achieved ( $\sim 3$ days). Capped vials containing the lipid samples were stored at $-10^{\circ} \mathrm{C}$ until analyzed. The mass of lipids recovered for each DDGS sample was calculated as the final weight of the lipids in the vial, plus the difference of its associated cup weight before extraction and after placing it in the convection oven. Lipid yields were calculated by dividing the mass of lipids extracted by the initial mass of the dry grain sample.
Compositional Analysis of Plant Sterols and Policosanols

The analyses of PC and PS levels and compositions in the lipid extracts were conducted by using a GC method. An example chromatogram is shown in Figure 1. Preparation of the samples for the GC analysis consisted of dissolving the internal standards, $5 a-c h o l e s t a n e$ (Steraloids Inc., Newport, RI, USA) and PC $\mathrm{C}_{27}$ (Ultra Scientific Inc., Kingstown, RI, USA), in chloroform at a final concentration of $\sim 100 \mu \mathrm{g} / \mathrm{mL}$. Each sample $(0.02 \mathrm{~g})$ was weighed into a $20-\mathrm{mL}$ vial and followed by addition of $1 \mathrm{ml}$ of $5 \mathrm{a}$-cholestane and $0.1 \mathrm{ml}$ of policosanol $\mathrm{C}_{27}$. The chloroform was evaporated in a heating block $\left(\sim 60^{\circ} \mathrm{C}\right)$ under $\mathrm{N}_{2}$ and then the samples were allowed to cool for $3 \mathrm{~min}$. The samples were saponified with $1 \mathrm{~mL}$ of methanolic $\mathrm{KOH}(1 \mathrm{M})$, and the mixture was heated to $50^{\circ} \mathrm{C}$ in a heating block for $1 \mathrm{~h}$ with occasional agitation. Nonsaponifiable lipids were extracted by adding $1 \mathrm{~mL}$ of deionized water followed by addition of $2 \mathrm{~mL}$ of hexane to each sample, which was then shaken and centrifuged $(370 \times g)$ for $\sim 2 \mathrm{~min}$.

The hexane phase was transferred to a $10-\mathrm{mL}$ vial and the hexane evaporated under $\mathrm{N}_{2}\left(\sim 60^{\circ} \mathrm{C}\right)$. The samples were derivatized by adding $50 \mu \mathrm{L}$ of Sylon BTZ (Supelco, Bellefonte, PA, USA), and allowed to stand for at least $20 \mathrm{~min}$ at room temperature before being analyzed. The GC conditions were: $0.32 \mathrm{~mm} \times 30 \mathrm{~m}$ DB- 5 capillary column (J \&W Scientific, Folsom, CA, USA); initial temperature, $100^{\circ} \mathrm{C}$ for $0.5 \mathrm{~min}$, increasing to $300^{\circ} \mathrm{C}$ at $5^{\circ} \mathrm{C} / \mathrm{min}$; injector temperature, $270^{\circ} \mathrm{C}$; flame ionization detector temperature, $300^{\circ} \mathrm{C}$; He carrier gas; and split ratio, 50:1.

Sitosterol, stigmasterol, campesterol (Steraloids Inc. Newport, RI, USA) and policosanols $\left(\mathrm{C}_{26^{\prime}}, \mathrm{C}_{28}\right.$ and $\left.\mathrm{C}_{32}\right)$ (Ultra Scientific Inc., Kingstown, RI, USA) compounds were identified by comparing retention times with pure compounds. Amounts of sitosterol, stigmasterol, campesterol and policosanols $\left(\mathrm{C}_{26}, \mathrm{C}_{28}\right.$ and $\left.\mathrm{C}_{32}\right)$ in the lipid extracts, were determined based on the internal standard method.

A parallel study completed at the University of $\mathrm{Ne}-$ braska-Lincoln, also determined PS levels from samples of the same ground grain sorghum and sorghum DDGS using the acid and alkaline hydrolysis prior to GC analysis method of Piironen et al. [9]. Briefly in this method after the initial addition of the internal standard (5acholestane), $\mathrm{HCl}(6 \mathrm{M})$ was added to the samples, agitated and then kept in a shaken water bath for $60 \mathrm{~min}$ at $80-85^{\circ} \mathrm{C}$. After cooling, extraction of lipids using hexane and diethyl ether (1:1) was performed. The organic layer was separated by centrifugation and then the solvents evaporated. Saponification with $\mathrm{KOH}(1 \mathrm{M})$ followed and further preparation for GC analysis continued as described above. 


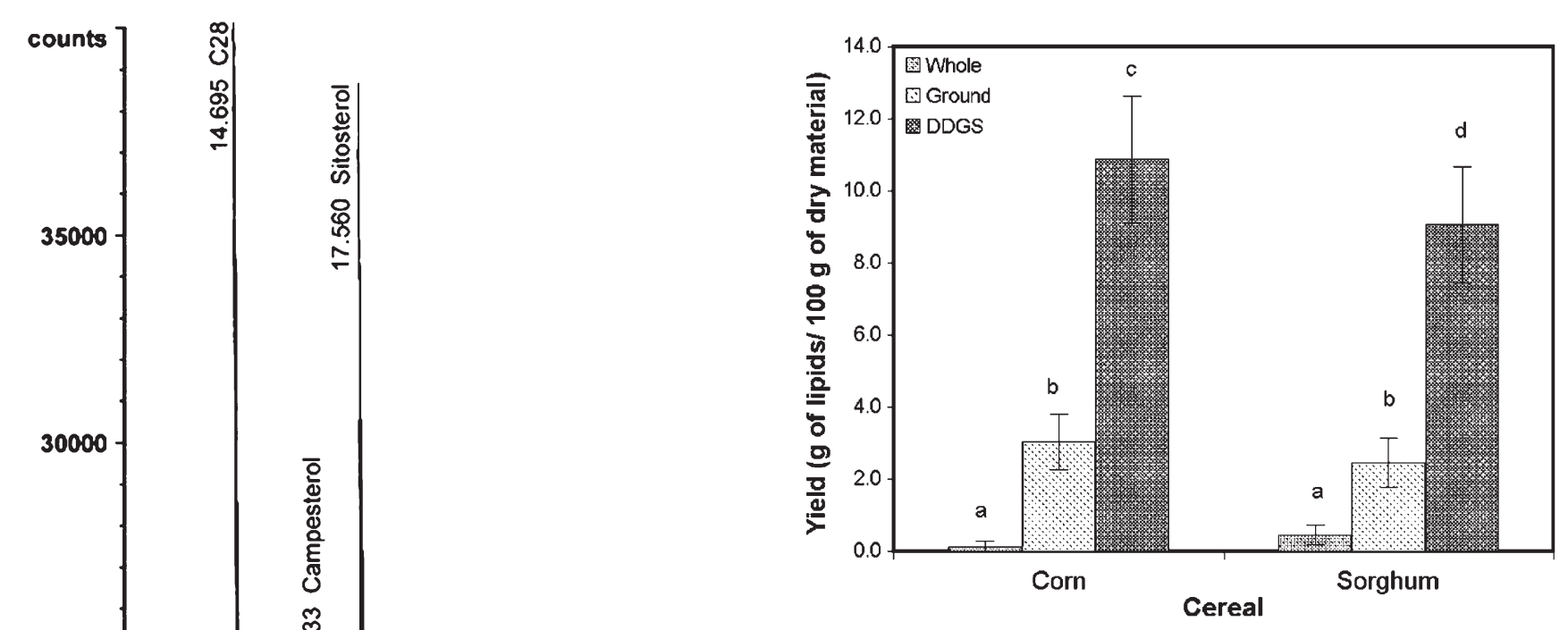

Figure 2. Total lipids yields extracted from various forms of grain sorghum and corn with hexane. No significant differences among bars with the same letter.

composition analyses were performed at least in triplicate for each treatment combination and sample, respectively. Values used in the comparisons and analysis of variance (ANOVA) table were calculated using the Proc Mixed Model procedure of SAS (SAS Software Version 9.1.). A least square means test with a significance level of $p<0.05$ was used for the comparisons of significant means.

\section{Results and Discussion \\ Lipids}

According to the statistical analysis of total lipid yields obtained for each treatment combination, the three way interaction (i.e., method $\times$ cereal $\times$ form) was not significant and only the two-way interactions (form $\times$ method; form $\times$ cereal) were significant. Therefore, the effect of the treatment combinations on the lipid yields cannot be analyzed as result of one nor three treatments but rather had to be analyzed as the effect of the "form $\times$ cereal" and "form $\times$ method" interaction. Influence of the form of the cereal on the corn and grain sorghum extracted lipid yields (form $\times$ cereal interaction) are shown in Figure 2. Differences in the amounts of lipids recovered from the three forms were significant for each cereal. As expected, yields for the DDGS forms were highest for both grain sorghum and corn as non-starch compounds are concentrated following fermentation. DDGS lipids were approximately four times greater than those obtained from the ground cereals at the observed particle size distributions. Particle size for the ground samples of the cereals ranged

from 0.075 to $2.36 \mathrm{~mm}$ with $\sim 60 \%$ of the particles being tical analysis. The response variables were lipid, plant sterols, and policosanol yields. Extractions and PC/PS 
between 0.85 and $1.7 \mathrm{~mm}$ for grain sorghum, and about $90 \%$ of the particles being between 0.3 and $1.18 \mathrm{~mm}$ for corn.

Lipid yields obtained from ground cereals and the DDGS forms were higher than those from the whole kernels as was expected. Once the starch-protein matrix in whole kernels was broken by grinding and subsequent fermentation, the solvent came readily in contact with inner kernel parts and extracted soluble compounds due to increased surface area (i.e., increased interface mass transfer). Similarly, Christiansen et al. [21] demonstrated that greater lipid yields were extracted from the ground kernels of nine different lines of grain sorghum compared to the whole kernels by using hexane with a Soxtec method. Lipid yields reported by Christiansen et al. [21] ( $\sim 0.5 \%$ d.b. for the whole forms and $\sim 3 \%$ d.b. for the ground forms) were comparable to those obtained in this study except that the Soxtec extraction differed slightly, such as the volume of hexane and time of extraction used.

Lipid yields from ground corn and corn DDGS exceeded those of their counterpart sorghum samples (Figure 2); however, significant differences only occurred between corn DDGS and sorghum DDGS with 15\% more lipids being recovered from corn DDGS. Greater lipid yields from corn compared to sorghum were expected as the amount of lipids in corn is typically slightly larger than that in grain sorghum [22]. Furthermore, most of the lipids in corn are in the germ, which constitutes about $12 \%$ of the kernel, whereas in sorghum the germ constitutes about $10 \%$ of the kernel [22]. Lipid extracts from corn DDGS were more oily (less viscous) than lipid extracts from sorghum DDGS. Moreover, differences exist in the compositions between the extracts from sorghum and corn DDGS, specifically in the wax compositions, as described in the following sections.

Total lipid yields from the whole and ground kernels of the two grains, and their DDGS forms as influenced by the method of extraction are shown in Figure 3. In most cases, the amount of lipids extracted by the Soxtec method exceeded those extracted using the reflux method; however, differences in lipid yields were only significant for the ground and DDGS forms indicating that the method of extraction does not affect lipid yields of whole kernels. Membrado et al. [23] attributed the higher performance of the Soxtec method, compared to the reflux method, to favored mass transfer due to the two steps involved in the operation of this method. After the boiling step, where the sample was submerged in the solvent, the Soxtec method included a rinsing step, where "clean" solvent condensed over the sample. Lipids that are not extracted during the boiling step as a result of possible solvent saturation are then extracted in the rinsing step. Conversely, in the reflux method the solids are in contact with the

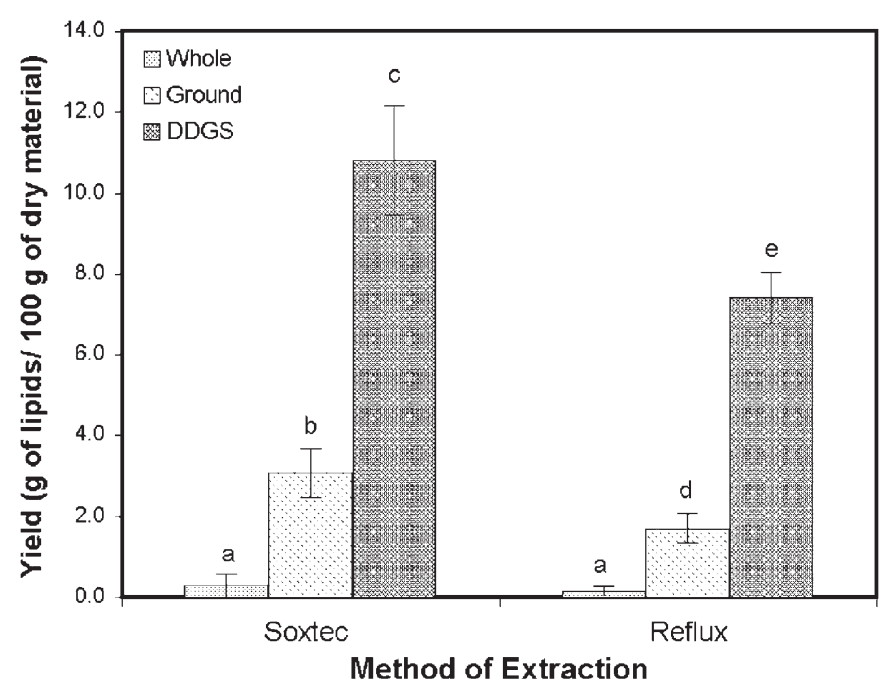

Figure 3. Total lipid yields extracted from various forms of two cereal grains (corn and grain sorghum) obtained by two methods of extraction (Soxtec and reflux). No significant differences among bars with the same letter.

boiling solvent during the entire extraction; as the extraction proceeds, potential for lipids to solubilize in the solvent is reduced.

For each method studied, lipid recovery yields among the three forms (whole kernels of grain, ground kernels of grain and DDGS) were significantly different. DDGS forms yielded the greatest amount of lipids, whereas whole forms yielded the lowest. Therefore, the grain form is an important parameter to consider in the operation of an extraction apparatus.

Even though significant differences in lipids yields were observed to be influenced by the interaction form $\times$ cereal, and the interaction form $\times$ method, caution needs to be taken in how the results of this study may be used. As the whole kernel and ground grain sorghum and yellow dent corn samples were not from the same source as their corresponding DDGS samples nor were they representative of all types of each cereal, some varietal, hybrid, production, and post-harvest processing differences were not fully accounted for in the experimental design. General observations related to presence and relative amount of lipids may be appropriate.

\section{Plant Sterols}

Given the low-lipid levels extracted from whole kernels, samples obtained on different days would have had to be combined to obtain the 2-mg sample size required for GC analysis. Thus, PS analyses of the whole kernels were not included in this study.

Total PS levels present in each extract ranged from 6.6 (ground corn Soxtec) to $11.5 \mathrm{mg}$ of total PS/g of lipid (corn DDGS Soxtec). Total PS extracted from $100 \mathrm{~g}$ 


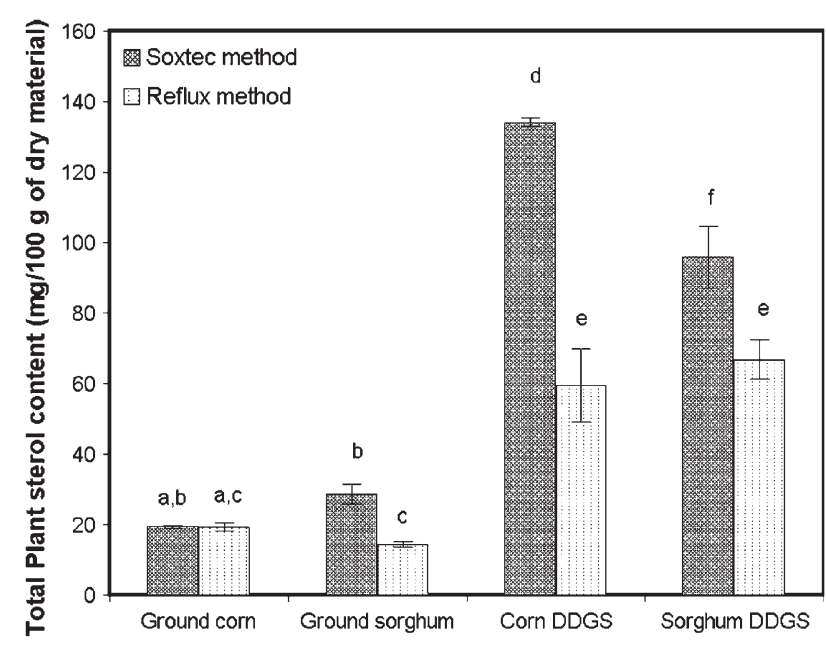

Figure 4. Total plant sterol contents (sum of sitosterol, campesterol and stigmasterol) of two forms of grain sorghum and corn obtained by two methods of extraction (Soxtec and reflux). No significant differences among bars with the same letter.

of dry grain material is shown in Figure 4. The greatest amounts of PS were extracted from both corn and sorghum DDGS. Amounts recovered from the corn DDGS and sorghum DDGS were significantly different for the Soxtec extracted samples, which reached 134.06 and $95.8 \mathrm{mg} / 100 \mathrm{~g}$ of DDGS, respectively; however, when the reflux method was used, the differences between cereal DDGS were not significant.

Although PS yields were significantly different between the Soxtec extracted ground forms of grain sorghum and corn (Figure 4), PS levels obtained by the reflux method were similar for grain sorghum and corn. In general, greater amounts of PS were extracted using the Soxtec method than using the reflux method. Comparison between the ground and DDGS forms from either corn and grain sorghum shows that DDGS contains approximately four times more PS than dry ground grains indicating that DDGS is an attractive "raw material" for the extraction of PS.

With the exception of the reflux-extracted sorghum whole kernel, sitosterol was the predominant sterol for all the samples (Table 1) accounting for $50 \%$ or more of the total PS. Similar predominance of sitosterol has also been observed by Winkler et al. [17]. Brassicasterol was also identified in some of the samples but only at trace levels. Prevalence of sitosterol, campesterol and stigmasterol among other PS is common in nature [6]. Contrary to the observations of this study, Christiansen et al. [21] reported stigmasterol to be the major plant sterol in whole kernel extracts of nine different parent lines of grain sorghum. Initially the same GC method as used by Christiansen et al. [21] was used in this study. However, it was determined that the stigmasterol and PC C30 could not be differentiated through use of this method. Given that Christiansen et al. [21] were not analyzing for policosanols, co-elution between stigmasterol and C30 peaks may have occurred and thus compromised the accuracy of the stigmasterol quantification. Modifications to the method of Christiansen et al. [21] to separate stigmasterol and C30 peaks might explain the higher sitosterol levels reported in the present study.

Cereal PS can be present in the free or conjugated forms. The conjugated forms contain another side chain, commonly replacing the alcohol moiety (C3) (Figure 5). Depending on the structure of the side chain at C3, plant sterols are be referred as: sterylglycosides, acylated sterylglycosides, long-chain fatty acid ester of sterol and steryl ferulates [24]. Typical chromatographic methods only identify the free form of the sterols. To release the additional side chain on C3 and obtain the correspondent "free" sterol, enzymatic, alkaline or acid hydrolysis can be used during the preparation of a sample before analysis by chromatography $[9,25]$. If a hydrolysis step, acidic or enzymatic, is included, sterylglycosides and acylated glycosides attached at C3 are released. Additionally, if a saponification step is included, compounds esterifying the sterols are also released [9]. Therefore, hydrolysis and saponification steps during the sample preparation procedure will influence the amount of free sterols present in a sample.

For example, if a hydrolysis step is included, the total content of PS obtained will be higher than that obtained without this step. Piironen et al. [9] reported total plant sterol content of selected Finish cultivars of barley, rye and oats using an analytical method that included an acid hydrolysis step. Among these cereals, rye contained the highest amount of plant sterols $(95.5 \mathrm{mg} / 100 \mathrm{~g})$, followed by barley $(76.1 \mathrm{mg} / 100 \mathrm{~g})$ and wheat $(69.0 \mathrm{mg} /$ 100 g). A parallel study completed at the University of Nebraska-Lincoln, determined PS levels from samples of the same ground grain sorghum and sorghum DDGS by the Piironen et al. [9] method, using acid and alkaline hydrolysis prior to analysis. The amount of total PS recovered by this double hydrolysis method was about $50 \%$ greater than the values obtained by either type of extraction alone (Table 2).

Additionally, Srinivasan et al. [16] investigated PS levels in corn DDGS using the extraction method of Singh et al. [15], which consisted of an accelerated solvent extractor. The PS levels reported were greater (216 mg of total PS/100 g of corn DDGS) than those reported in this study. These different results may again be attributed to the PS analysis that was used by Srinivasan et al. [16]. For the latter study, two HPLC methods that were capable of detecting free sterols, steryl ferulates and long-chain fatty acid esters of sterol were applied to the samples. Singh et al. [15] compared extracts from corn and grain sorghum kernels, similar to the present study, and reported greater amounts of PS in ground corn (88.01 mg of total PS/100 g) than in ground 

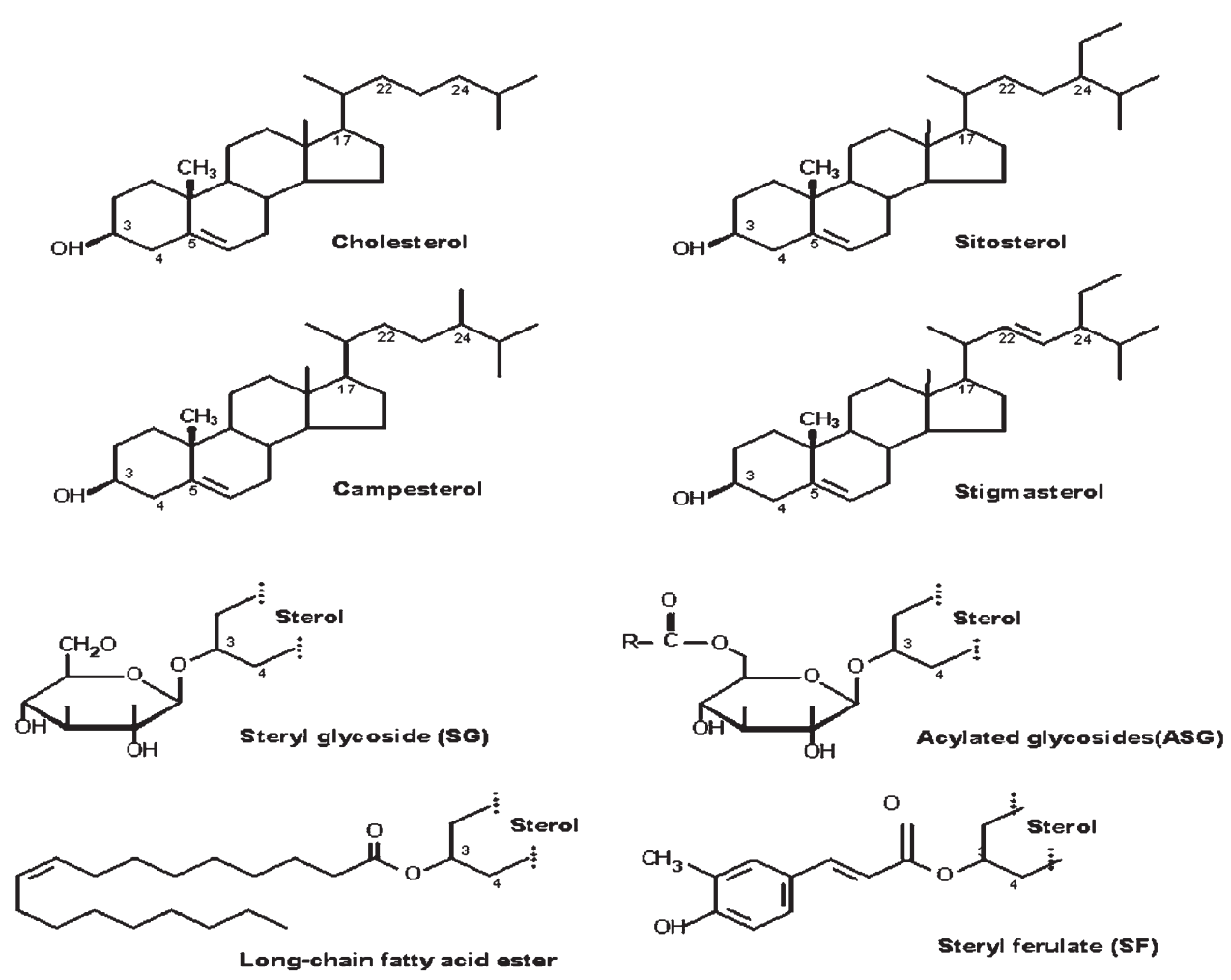

Figure 5. Typical free and conjugated sterol structures.

Table 1. Plant sterols composition in the lipid extracts of grain sorghum and corn at the forms whole and ground grain and DDGS obtained by two methods of extraction (Soxtec and reflux) (mg/g of lipids)

\begin{tabular}{|c|c|c|c|c|c|c|}
\hline \multirow[t]{2}{*}{ Sterol $^{\mathrm{a}}$} & \multicolumn{2}{|c|}{ Whole kernel } & \multicolumn{2}{|c|}{ Ground kernel } & \multicolumn{2}{|l|}{ DDGS } \\
\hline & Corn & Sorghum & Corn & Sorghum & Corn & Sorghum \\
\hline \multicolumn{7}{|c|}{ Soxtec extraction } \\
\hline Campesterol & $1.34 \pm 0.19$ & $1.04 \pm 0.04$ & $1.54 \pm 0.05$ & $2.86 \pm 0.28$ & $2.45 \pm 0.04$ & $2.54 \pm 0.24$ \\
\hline Stigmasterol & $0.68 \pm 0.12$ & $1.02 \pm 0.04$ & $0.45 \pm 0.02$ & $1.73 \pm 0.18$ & $0.88 \pm 0.04$ & $1.21 \pm 0.11$ \\
\hline Sitosterol & $4.76 \pm 0.91$ & $1.92 \pm 0.09$ & $4.60 \pm 0.10$ & $5.66 \pm 0.57$ & $8.17 \pm 0.13$ & $6.04 \pm 0.57$ \\
\hline \multicolumn{7}{|c|}{ Reflux Extraction } \\
\hline Campesterol & $1.26 \pm 0.19$ & $0.97 \pm 0.37$ & $2.46 \pm 0.15$ & $2.69 \pm 0.18$ & $1.58 \pm 0.26$ & $2.52 \pm 0.2$ \\
\hline Stigmasterol & $0.85 \pm 0.21$ & $1.08 \pm 0.30$ & $0.71 \pm 0.05$ & $1.74 \pm 0.06$ & $0.58 \pm 0.11$ & $1.18 \pm 0.10$ \\
\hline Sitosterol & $3.31 \pm 0.42$ & $0.93 \pm 0.33$ & $6.97 \pm 0.45$ & $5.07 \pm 0.29$ & $5.31 \pm 0.94$ & $6.04 \pm 0.52$ \\
\hline
\end{tabular}

a Values are means \pm standard deviation of at least nine analytical determinations for each treatment $(\geq 3$ det. $\times 3$ reps)

Table 2. Total plant sterol content means (sum of campesterol, stigmasterol and sitosterol) of grain sorghum extracts obtained by three different methods of extraction and sample preparation before analysis by GC (mg/100 g of material (wb))

\begin{tabular}{lll}
\hline Extraction method with sample preparation & Grain \\
\cline { 2 - 3 } & $\begin{array}{l}\text { Ground sorghum } \\
\text { (S. bicolor: Macia) }\end{array}$ \\
\hline Reflux extraction before alkaline hydrolysis & $12.51 \pm 0.68$ & $57.43 \pm 4.82$ \\
Soxtec extraction before alkaline hydrolysis & $24.85 \pm 2.50$ & $82.41 \pm 7.68$ \\
Plant material was subjected to acid and alkaline hydrolysis before solvent extraction & $53.59 \pm 4.69$ & $137.34 \pm 11.43^{\text {a }}$ \\
\hline
\end{tabular}

a Sorghum DDGS was ground before hydrolysis and solvent extraction 


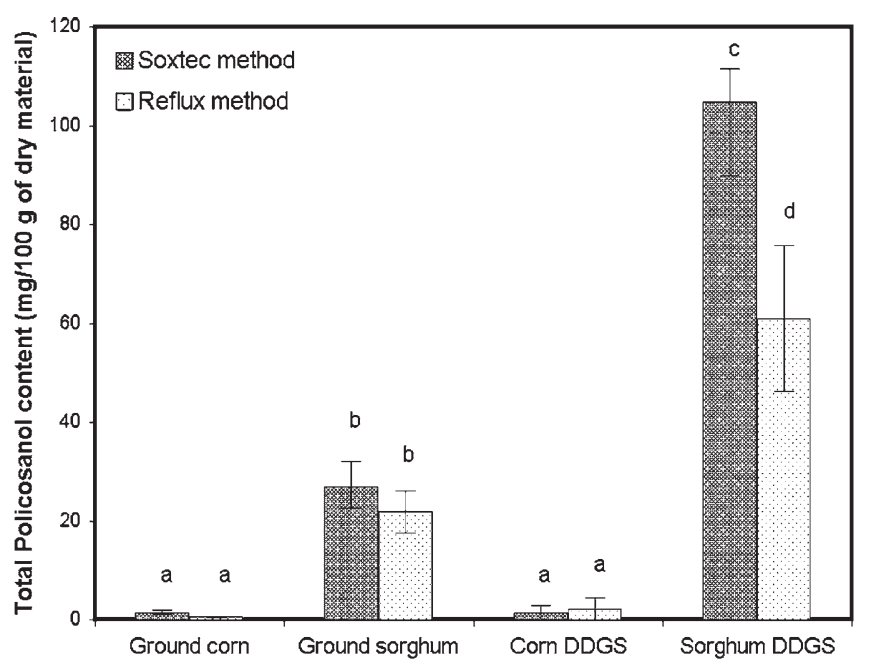

Figure 6. Total policosanol contents (sum of C26, C28, C30, and C32) of two forms of grain sorghum and corn obtained by two methods of extraction (Soxtec and reflux). No significant differences among bars with the same letter.

grain sorghum ( $48.4 \mathrm{mg}$ of total PS/100 g, average of two grain sorghum hybrids).

More recently, Winkler et al. [17] compared five different combinations of methods and solvents to extract PS from corn DDG. They observed levels of PS in corn DDG ranging from 192 to $291 \mathrm{mg}$ of total PS/100 g of corn DDG. The PS levels reported were greater than the value of $134.06 \mathrm{mg}$ of total PS/100 g of corn DDGS reported in this study. Longer extraction time and use of accelerated solvent extractions by Winkler et al. [17] probably contributed to their greater observed values.
Review of the literature demonstrates that researchers have used different techniques to extract lipids from cereals, and the identification and quantification of plant sterols in the extracts; however, the effects of different PS levels for each extracts on their absorption in the gastrointestinal track and their capacity to lower plasma cholesterol levels after consumption has yet to be investigated.

\section{Policosanols}

Extracts of corn/grain sorghum whole kernels, corn/ grain sorghum ground kernels, corn/grain sorghum DDGS obtained by reflux and Soxtec method were analyzed to determine PC compositions of the extracts. Given the small amounts of lipids extracted from whole kernels, the whole forms of the cereals were not included in the analysis for PC content.

The PC content (sum of C26, C28, C30, and C32) for each of the extracts is shown in Figure 6. C34 was also identified in some of the samples but only at trace levels. Minimal levels of PC were extracted from corn as compared to grain sorghum for all the forms studied. These results support the waxy nature of sorghum extracts compared to the oily appearance of corn extracts. Among the three forms studied, the greatest amounts of PC were recovered from DDGS using either of the two extraction methods. Policosanol yields of sorghum DDGS obtained from the two methods were significantly different; although they were not significant for the ground form. On average, the amount of PC extracted from sorghum DDGS was three times more than

Table 3. Policosanol composition in the lipid extracts of corn and sorghum at the forms whole, ground, and DDGS obtained by two methods of extraction (Soxtec and reflux) (mg/g of lipids)

\begin{tabular}{|c|c|c|c|c|c|c|}
\hline \multirow[t]{2}{*}{ Policosanol $^{a}$} & \multicolumn{2}{|c|}{ Whole kernel } & \multicolumn{2}{|c|}{ Ground kernel } & \multicolumn{2}{|l|}{ DDGS } \\
\hline & Corn & Sorghum & Corn & Sorghum & Corn & Sorghum \\
\hline \multicolumn{7}{|c|}{ Soxtec extraction } \\
\hline $\mathrm{C} 26$ & $0.60 \pm 0.36$ & $1.53 \pm 1.51$ & n.d. & $1.16 \pm 0.15$ & Trace $^{b}$ & $1.08 \pm 0.09$ \\
\hline $\mathrm{C} 28$ & $2.27 \pm 1.06$ & $2.70 \pm 2.24$ & $0.263 \pm 0.045$ & $4.76 \pm 0.89$ & Trace $^{b}$ & $4.73 \pm 0.27$ \\
\hline C 30 & $1.25 \pm 0.50$ & $1.31 \pm 0.76$ & $0.173 \pm 0.151$ & $3.25 \pm 0.83$ & Trace $^{b}$ & $4.43 \pm 0.46$ \\
\hline $\mathrm{C} 32$ & $0.49 \pm 0.12$ & $0.25 \pm 0.22$ & n.d. & $0.50 \pm 0.08$ & Trace $^{b}$ & $0.45 \pm 0.05$ \\
\hline \multicolumn{7}{|c|}{ Reflux extraction } \\
\hline $\mathrm{C} 26$ & $0.65 \pm 0.19$ & $4.62 \pm 1.29$ & Trace $^{b}$ & $1.59 \pm 0.26$ & Trace $^{b}$ & $1.01 \pm 0.17$ \\
\hline $\mathrm{C} 28$ & $1.48 \pm 0.31$ & $9.69 \pm 2.46$ & Trace $^{b}$ & $7.21 \pm 1.39$ & Trace $^{b}$ & $4.01 \pm 0.92$ \\
\hline $\mathrm{C} 30$ & $1.08 \pm 0.17$ & $3.99 \pm 0.79$ & Trace $^{b}$ & $5.06 \pm 1.16$ & Trace $^{b}$ & $3.49 \pm 1.00$ \\
\hline C32 & $0.36 \pm 0.32$ & $0.52 \pm 0.11$ & $0.11 \pm 0.03$ & $0.61 \pm 0.09$ & Trace ${ }^{b}$ & $0.38 \pm 0.08$ \\
\hline
\end{tabular}

n.d. not detected

a Values are means \pm standard deviation of at least nine analytical determinations for each treatment $(\geq 3$ det. $\times 3$ reps)

$\mathrm{b}$ Trace amounts were reported for samples with a mean $<0.1 \mathrm{mg} / \mathrm{g}$ of lipids 
that of ground grain sorghum. Irmak et al. [10] investigated PC levels in different fractions of wheat and showed that the highest amount of PC recovered was $0.628 \mathrm{mg} / \mathrm{g}$, extracted from precipitates of wet germ oil after treatment with diethyl ether. This level was lower than that obtained from grain sorghum. To our knowledge, no other studies have been published that investigated PC levels in cereals.

Table 3 provides the compositional PC profiles (C26, C28, C30, and C32) in the lipid extracts for each sample. Policosanol composition in the extracts varied significantly. In general, C28 was the most abundant PC (around $45 \%$ of the total PC) in all extracts, where C32 was the least abundant. Hwang et al. [26] also showed that C28 is the major PC in grain sorghum kernels and sorghum DDGS extracts. In addition, Irmak et al. [10] reported C24, C26 and C28 to be the main PC compounds in most of the wheat extracts.

\section{Conclusions}

Lipid yields from the corn sources were typically greater than those obtained from corresponding grain sorghum sources. Lipid yields from DDGS were the highest among all the forms of the grains used whereas corn DDGS and grain sorghum DDGS contained the highest levels of plant sterols and policosanols, respectively. Increased levels of total extractable plant sterols from grain sorghum and sorghum DDGS are possible through use of acidic and alkaline hydrolysis. Overall, the Soxtec method of extraction resulted in greater amounts of extracted lipids than the amounts from the reflux extraction method.

\section{Acknowledgments}

This manuscript is a contribution of the University of Nebraska Agricultural Research Division, supported in part by funds provided through the Hatch Act, USDA. Additional support was provided by the USDA-CSREES-National Research Initiative Competitive Grants Program (grant no. 2004-35503-14824) and USDA-ARS Specific Cooperative Agreement 58-5430-4-362. Mention of a trade name, proprietary products, or company name is for presentation clarity and does not imply endorsement by the authors or the University of Nebraska. The authors thank Dr. Ismail M. Dweikat for providing sorghum samples, Dr. David S. Jackson for providing the corn samples, Dr. Laura Nyström from the Department of Applied Chemistry and Microbiology at the University of Helsinki for her work on measurement of sterols using acid hydrolysis and Dr. David B. Marx and Makram J. Geha from the Department of Statistics at the University of Nebraska, Lincoln for guidance and assistance with the experimental design and statistical analysis.

\section{References}

1. Simpson TW, Sharpley AN, Howarth RW, Paerl HW, Mankin KR (2008) The new Gold Rush: fueling ethanol production while protecting water quality. J Environ Qual 37:318-324

2. Taylor JRN, Schober TJ, Bean SR (2006) Novel food and non-food uses for sorghum and millets. J Cereal Sci 44:252271

3. Hoffman LA, Baker A, Foreman L, Young E (2007) Feed grains backgrounder. USDA Economic Research Service. http://www.ers.usda.gov/Publications/FDS/2007/ 03Mar/FDS07C01/. Accessed November 2007

4. Awika JM, Rooney LW (2004) Sorghum phytochemicals and their potential impact on human health. Phytochem 65:1199-1221

5. Hwang KT, Cuppett SL, Weller CL, Hanna MA (2002) Properties, composition and analysis of grain sorghum wax. J Am Oil Chem Soc 79:521-527

6. Ostlund RE (2002) Phytosterols in human nutrition. Ann Rev Nutr 22:533-549

7. Lewis C (2000) Health claim for foods that could lower heart disease risk. FDA Consumer magazine. November-December http://www.fda.gov/FDAC/features/2000/600 claims.html. Accessed February 2008

8. [EuFIC Org] European Food Information Council (2007) Plant sterols and stanols - proven to lower cholesterol. http:// www.eufic.org/article/en/artid/plant-sterols-stanolscholesterol/. Accessed July 2007

9. Piironen V, Toivo J, Lampi A-M (2002) Plant sterols in cereals and cereal products. Cereal Chem 79:148-154

10. Irmak S, Dunford NT, Milligan J (2006) Policosanol contents of beeswax, sugar cane and wheat extracts. Food Chem 95:312-318

11. Gouni-Berthold I, Berthold HK (2002) Policosanol: clinical pharmacology and therapeutic significance of a new lipidlowering agent. Am Heart J 143:356-365

12. Carr K (1999) Cuban biotechnology treads a lonely path. Nature 398:22-23

13. Marinangeli CPF, Kassis AN, Jain D, Ebine N, Cunnanne SC, Jones PJH (2007) Comparison of composition and absorption of sugarcane policosanols. Br J Nutr 97:381-388

14. Carr TP, Weller CL, Schlegel VL, Cuppett SL, Guderian DM, Johnson KR (2005) Grain sorghum lipid extract reduces cholesterol absorption and plasma non-HDL cholesterol concentration in hamsters. J Nutr 135:2236-2240

15. Singh V, Moreau RA, Hicks KB (2003) Yield and phytosterol composition of oil extracted from grain sorghum and its wet-milled fractions. Cereal Chem 80:126-129

16. Srinivasan R, Moreau RA, Rausch KD, Tumbleson ME, Singh V (2007) Phytosterol distribution in fractions ob- 
tained from processing of distillers dried grains with solubles using sieving and elutriation. Cereal Chem 84:626-630

17. Winkler JK, Rennick KA, Eller FJ, Vaughin SF (2007) Phytosterol and tocopherol components in extracts of corn distiller's dried grain. J Agric Food Chem 55:6482-6486

18. Wang L, Weller CL, Hwang KT (2005) Extraction of lipids from grain sorghum DDG. Trans ASAE 48:1883-1888

19. Soupas L, Juntunen L, Lampi A, Piironen V (2004) Effects of sterols structure, temperature and lipid medium on phytosterol oxidation. J Agric Food Chem 52:6485-6491

20. Christiansen K (2006) Understanding the parameters affecting lipid extraction from grain sorghum. M.S. Thesis. University of Nebraska-Lincoln

21. Christiansen KL, Weller CL, Schlegel VL, Cuppett SL, Carr TP (2007) Extraction and characterization of lipids from the kernels, leaves, and stalks of nine grain sorghum parent lines. Cereal Chem 84:463-470
22. Hoseney RC (1994) Principles of cereal science and technology, vol 2. AACC Inc, St. Paul, MN

23. Membrado L, Vela J, Ferrando AC, Cebolla VL (1996) Improved extraction procedures for coal products based on the Soxtec apparatus. Energy Fuels 10:1005-1011

24. Moreau RA, Whitaker BD, Hicks KB (2002) Phytosterols, phytostanols, and their conjugates in foods: structural diversity, quantitative analysis, and health-promoting uses. Prog Lipid Res 41:457-500

25. Nyström L, Moreau AR, Lampi A, Hicks KB, Piironen V (2008) Enzymatic hydrolysis of steryl ferulates and steryl glycosides. Eur Food Res Technol 227:727-773

26. Hwang KT, Weller CL, Cuppett SL, Hanna MA (2004) Policosanol contents and composition of grain sorghum kernels and dried distillers grains. Cereal Chem 81:345-349 